ror

SECCIÓN: Teorías geográficas, geografía de la cultura y la vida cotidiana
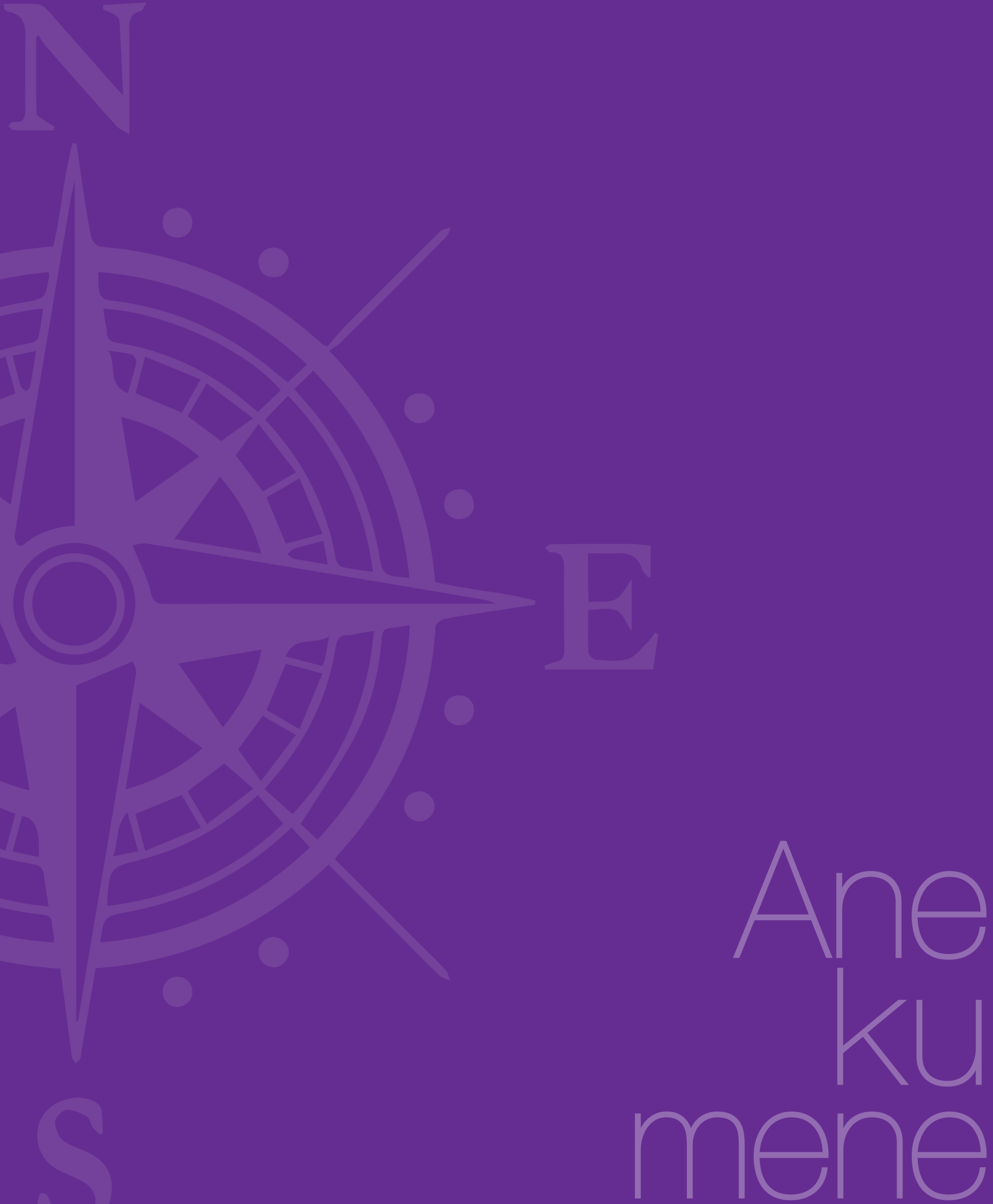


\title{
O Caldeirão de Santa Cruz do Deserto: prática pedagógica em instalações geográficas
}

Caldero de la Santa Cruz del Desierto: práctica pedagógica en instalaciones geográficas

\section{Caldeirão de Santa Cruz do Deserto: Pedagogical Practice in Geographic Facilities}

\author{
Emerson Ribeiro*
}

\section{Resumo}

A prática pedagógica a qual iremos abordar nesse texto foi realizada com os alunos da disciplina de Estágio Supervisionado III, Economia Política I e Antropologia na Universidade Regional do Cariri com a proposta de ser interdisciplinar. Devemos salientar que a proposta seguiu a programação até a realização de um campo para o Caldeirão de Santa Cruz do Deserto, município do Crato, Ceará. Os alunos da geografia além de apresentar no relatório de estágio os relatos de atividades, realizou como processo de avaliação, sendo esta uma instalação geográfica na Praça da Sé no município do Crato. Para o ensino de Geografia definimos a Instalação Geográfica como uma forma de representação de um conteúdo geográfico pesquisado e trabalhado criativamente com signos e símbolos aplicado sobre materiais produzidos ou não pelo homem. Essa instalação pode ser montada na escola/universidade ou para além de seus muros atingindo uma dimensão social.

* Universidade Regional do Cariri.

\section{Palavras-chave:}

instalações geográficas; prática pedagógica; ensino de geografia. 


\section{Resumen}

La práctica pedagógica que abordaremos en este texto se realizó con los estudiantes de Pasantía Supervisada III, Economía Política I y Antropología de la Universidad Regional de Cariri, Brasil. La propuesta consistió en la realización de una salida de campo para el Caldero de la Santa Cruz del Desierto, municipio de Crato, Ceará. Los estudiantes de geografía, además de presentar en el informe de pasantías la recopilación de actividades, realizadas como un proceso de evaluación, diseñaron una instalación geográfica en Praça da Sé en el municipio de Crato. Para la enseñanza de la geografía, definimos la instalación geográfica como una forma de representación de un contenido geográfico investigado y trabajado creativamente con signos y símbolos aplicados en materiales producidos o no por el hombre. Esta instalación se puede montar en la escuela/ universidad o más allá de sus paredes, alcanzando una dimensión social.

\section{Abstract}

The pedagogical practice that we will address in this text was carried out with the students of Supervised Internship III, Political Economy I and Anthropology at the Regional University of Cariri, Brazil. The proposal consisted of carrying out a field trip to Caldeirão de Santa Cruz do Deserto, municipality of Crato, Ceará. The geography students, in addition to presenting in the internship report the collection of activities, carried out as an evaluation process, designed a geographical installation in Praça da Sé in the municipality of Crato. For the teaching of geography, we define the Geographic Installations as a form of representation of a geographical content researched and creatively worked with signs and symbols applied in materials produced or not by man. This installation can be mounted in the school / university or beyond its walls, reaching a social dimension.

\section{Palabras clave:}

Instalaciones geográficas, práctica pedagógica, enseñanza de la geografía.

\section{Keywords:}

Geographical installations, pedagogical practice, geography teaching. 


\section{Exórdio}

Localizar o localizável é uma tarefa da geografia escolar também, a possibilidade de se utilizar os sentidos para a análise espacial, perpassa a sala de aula indo de encontro ao campo. Como essa prática aborda o Caldeirão de Santa Cruz do Deserto, um local desconhecido até mesmo das pessoas que vivem na região, é necessário abordar no texto uma cartografia simbólica e descritiva do local. Ao sul do Estado do Ceará encontra-se o município do Crato, dentro da Região Metropolitana do Cariri, onde a cidade polo é Juazeiro do Norte. Nessa região encontramos o complexo Crajubar, Crato, Juazeiro do Norte e Barbalha sendo essas as principais cidades da Região Metropolitana do Cariri.

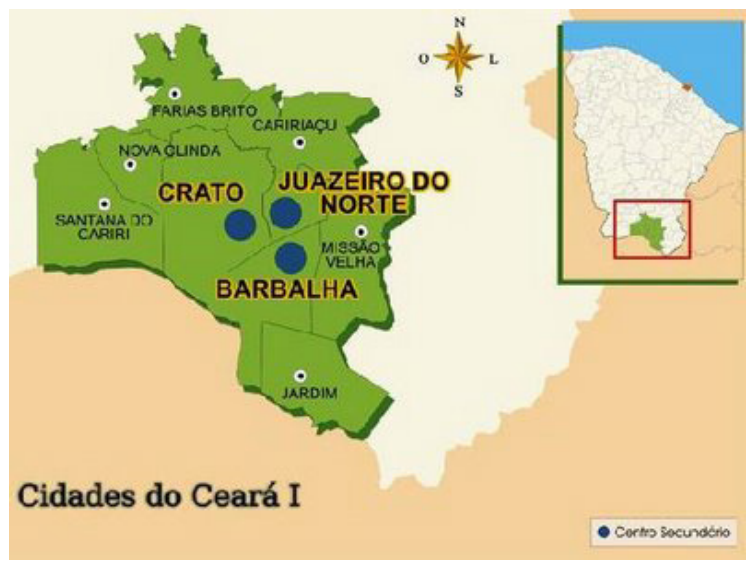

Figura 1. Região Metropolitana do Cariri

Fonte: Instituto Brasileiro de Geografia e Estadística (IBGE) (2018)

O Caldeirão localiza-se ao sul do estado do Ceará, no município do Crato na região metropolitana do Cariri. Em 1926 o Beato Jose Lourenço que fora amigo do padre Cicero, doa lhe as terras em que viria a ser chamado de Caldeirão. O Beato então viaja com alguns camponeses e inicia o cultivo nas terras doadas pela igreja, surgindo assim, o Caldeirão de Santa Cruz do Deserto. A comunidade ali abrigada passa a plantar, colher $e$ cuidar dos animais em conjunto em união sendo conduzido pelo Beato, em que tudo era de todos e a solidariedade se fazia presente.

Sobre a comunidade do Caldeirão foi necessário levantar alguns registros históricos, como pesquisas, artigos e jornais para elucidar algumas variáveis desconhecidos da história do Caldeirão. Com a publicação do livro Um Beato Líder - Narrativas Memoráveis do Caldeirão (Cordeiro, 2004), Sávio Cordeiro pesquisou sobre o messianismo brasileiro, iniciadas por Rui Facó (1976). Antônio Máspoli de Araújo Gomes (2009) escreve um artigo "A destruição da terra sem males: o conflito religioso do Caldeirão de Santa Cruz do Deserto" e a Gazeta do Cariri descreviam a sociedade da época e os interesses locais.

o Caldeirão e esse rito messiânico vivido em comunidade e liderado pelo beato José Lourenço foi também contada em vídeo: o documentário $O$
Caldeirão de Santa Cruz do Deserto, de Rosemberg Cariry (2001). Nesse filme estão registrados depoimentos de pessoas direta ou indiretamente envolvidas com os fatos, do lado tanto dos camponeses quanto das elites. Essas fontes o qual passamos aos nossos alunos para uma análise bibliográfica tanto das fontes primárias e secundárias (livros, periódicos, etc.), buscam contar a história do Caldeirão a partir das suas relações com a sociedade e com o sagrado. Além, das referências foi imprescindível à saída a campo, pois, para a metodologia que buscamos foi a interdisciplinar o estudo do meio se fez necessário para conhecer o local em que as histórias foram narradas.

O campo ocorreu no dia 13 de maio de 2016, aos alunos a tarefa de preparar o campo os pontos de parada, o que levar o tipo de vestimenta, o que registrar e documentar, foram instigados pelo professor a pensarem, pois como a disciplina em questão é estágio supervisionado um plano de aula de campo foi apresentado pelos alunos em grupo. Para localizar o caldeirão recorremos ao site de busca Google, uma ferramenta importante a ser utilizada para as aulas de geografia, pois permite a localização via satélite com certa precisão. O Caldeirão está distante do município do Crato $30 \mathrm{~km}$, esse trajeto apresenta um relevo de formas suaves e pouco dissecadas, como solo pedregoso, ainda nesse texto exploraremos melhor esse ponto.

Nessa primeira parte do texto apresentamos o localizável, os objetos e os sujeitos que irão nos acompanhar para a descrição dessa prática pedagógica, o que descreveremos abaixo serão os conteúdos os quais os alunos tiveram que apreender para dar sustentação à metodologia das Instalações Geográficas.

\section{Elementos para o Baldrame}

Apresentaremos nesse texto o processo, o caminho para trabalhar com as instalações geográficas. Devo salientar que o professor é um mediador diante do processo de ensino ao trabalhar com essa metodologia, os alunos em boa parte conduzem o processo de aprendizagem. Abaixo delinearemos a metodologia com as instalações geográficas e a sequência didática que nos levaram as instalações.

1. Num primeiro momento a partir de um conteúdo geográfico, em nosso caso o tema escolhido de forma interdisciplinar é o "Caldeirão de Santa Cruz do Deserto".

2. No segundo momento partimos para a produção de uma pesquisa, "essa decorre dos textos, periódicos, vídeo e estudo do meio" sobre a qual é elaborado um primeiro texto sobre o assunto abordado e apontando também o que irá ser materializado na instalação (aqui ainda podemos não saber no que vamos instalar o conhecimento apreendido). 
3. O terceiro momento acontece quando em decorrência da pesquisa é gerado um debate na sala de aula determinando o material a ser configurado com o conteúdo em estudo.

4. Para que num quarto momento, em uma data específica a instalação é montada pelos alunos e professor, para exposição/apresentação, e após a apresentação é desmontada, e finalizada com a produção de um novo texto sobre todo o processo.

Ainda não menos explicativo, mas necessário para apresentá-la, à sequência didática abordada foi a seguinte:

1. Em conjunto com os professores e alunos de geografia da economia e antropologia, apresentamos um documentário O Caldeirão de Santa Cruz do Deserto, de Rosemberg Cariry (2001). Esse vídeo teve para os professores de localizar no tempo e na história o Caldeirão para os alunos, também conversamos com os mesmos e expomos como seriam as aulas e os próximos encontros.

2. Após o documentário e debate sobre o vídeo, o próximo passo foi organizar em grupo as turmas, em que os alunos da geografia, economia e antropologia se misturaram, essa tarefa se deu em outro momento, cada grupo tinha um representante que ficou de organizar os contatos com os demais.

3. Cada grupo ficou de levantar uma pesquisa a respeito do Caldeirão, os alunos da geografia pesquisaram o solo, relevo, clima, vegetação e as relações sociais e econômicas da época, como também ficaram de produzir o croqui, para o relatório de estágio. Os alunos de economia abordaram o tema da depressão de 29 e os impactos no Ceará e Brasil, fazendo uma análise do local/global, os alunos da antropologia abordaram a relação do homem com o sagrado e o profano, aos professores a tarefa era fornecer a bibliografia preliminar, assim como tirar as dúvidas.

4. Após a elaboração pelos alunos de um roteiro de campo a data escolhida foi 13 de maio. Em que as três turmas saíram do município do Crato rumo ao Caldeirão de Santa Cruz do Deserto. 0 campo durou o dia todo com paradas nas vilas para explicação das formas do relevo, vegetação, clima e solo, assim como as atividades agrícolas e de pecuária, e conversas com moradores. Ao chegar ao Caldeirão fomos recebidos por Dona Maria (nome fictício) moradora que preserva e recebe os visitantes, junto com marido e filhos. Dona Maria nos recebeu e a vista começou pelo museu que há no lugar, porém este muito precário, pois não há investimento do setor público e da ordem dos Salesianos o qual o terreno pertence. Também visitamos a capela que há no local onde os moradores faziam as suas orações, e atrás da capela há um cemitério, e no caminho de solo pedregoso e vegetação de caatinga, mais adentro, encontramos o Caldeirão, uma fenda geológica de rochas cristalina abastecida por um lençol freático, antes de dar nome ao sítio que abrigou a irmandade liderada pelo beato José Lourenço.

5. Após o campo, professor e alunos refizeram o percurso de aprendizagem, em debate em sala de aula.

6. Para o processo de avaliação ficou a critério de cada professor a escolha da análise do conteúdo apreendido pelos alunos. Em nosso caso o processo de avaliação se deu pelas instalações geográficas.

O esforço aqui é uma tentativa de demostrar os passos dados para essa prática pedagógica. A seguir vamos expor o conteúdo abordado, e, não será possível apresentar o todo da pesquisa, mas sim a ideia central para a elaboração dessa prática pedagógica que nos conduz para a formação de professores em que pesa a nossa aposta também é de fomentar nos alunos a criação, o ato de inventar e criar uma aula baseada no processo de ensino e aprendizagem tendo como metodologia as instalações geográficas.

\section{0 alicerce}

O cariri cearense é uma região que se encontra no sul do Estado do Ceará, este está contido no Domínio Morfoclimático da Caatinga, onde predomina o clima Tropical semiárido. Para a apreensão do real o estudo do meio é uma metodologia de ensino interdisciplinar que pretende desvendar os elementos da paisagem de um determinado espaço, em constante transformação. Essa prática pedagógica interdisciplinar do estudo do meio permite que o professor e alunos se envolvam num processo de pesquisa. Leva-os a descobrir como uma gama de conteúdos já produzidos em muitas situações escolares, e em muitas vezes sem relação com a vivência, com o cotidiano do aluno, é saber como esses conteúdos são produzidos. Conduzir o aluno a dominar elementos da prática e da didática, assim, como fazer com que o mesmo descubra uma metodologia que os leves a pesquisa e a reflexão do ensino de geografia, podem ajuda-los a compreender melhor o espaço em que vivemos.

O local dessa prática interdisciplinar tem como subsídios o lugar e a paisagem da Chapada do Araripe, mais precisamente o sítio Caldeirão de Santa Cruz do Deserto no município do Crato em que uma abordagem interdisciplinar contribui para o desenvolvimento e conhecimento da região. As expressões culturais e condições geoambientais diferenciadas de outras partes do semiárido nordestino tem uma forte ligação à existência da Bacia Sedimentar do Araripe e sua população autóctone, os ameríndios Cariris. A presença da Chapada do Araripe, com uma altitude de cerca de $950 \mathrm{~m}$, e com seu barlavento voltado para a Região do Cariri Cearense contribui para existência de um ecossistema bastante rico em biodiversidade, como mostra a foto. 


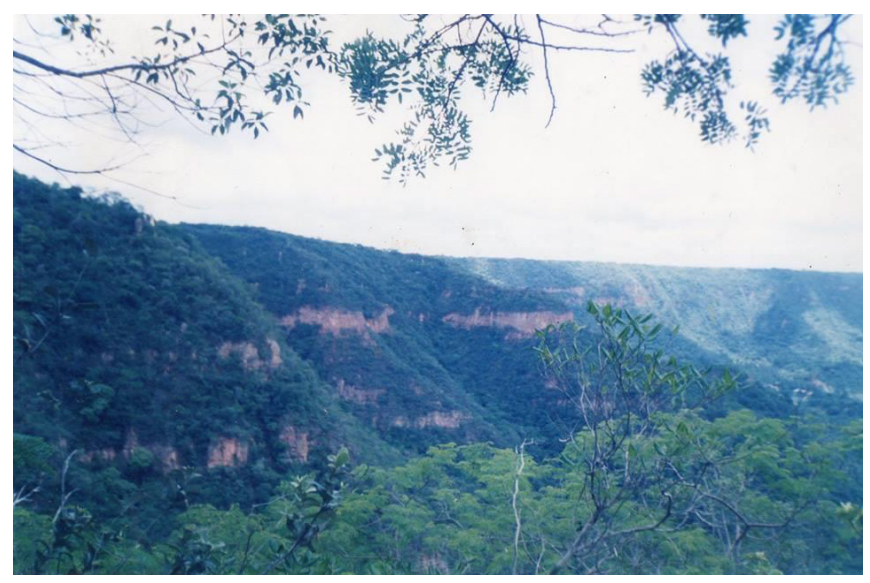

Figura 2. Chapada do Araripe, vertente para município do Crato Fonte: Arquivo do autor.

O historiador cratense Irineu Nogueira Pinheiro (2010), em seu livro o Cariri diz: "Sua vegetação sempre verde e suas águas perenes contrastam singularmente com os sertões semiáridos que o circundam" ( $p$. 7). O Cariri tem suas expressões culturais e condições geoambientais diferenciadas de outras partes do semiárido nordestino, que se expressam na paisagem a partir das tradições rurais, nos lugares da memória, na biodiversidade representativa da Floresta Nacional do Araripe, no potencial hídrico subterrâneo e nas suas jazidas fossilificas. Considerando essas especificidades no contexto do semiárido nordestino, são de fundamental importância à incorporação desses fatores, associados à dinâmica social, ao ensino de geografia da Região.

Distante uns $20 \mathrm{~km}$ da borda da chapada do Araripe o sitio Caldeirão ao norte se constitui pela depressão sertaneja por formas suaves, poucos dissecadas, com maciços residuais. Os solos da região são solos podzólicos, latos solos, litólicos e solos aluviais. Geologicamente, o substrato compõe-se de xistos, quartzitos, gnaisses e magmáticos do Pré-Cambriano indiviso, com conglomerados, arenitos, grauvacas e argilitos do cambriano, arenitos e calcários do Paleozoico. O clima é semiárido tropical seco e quente com quadra chuvosa no verão/outono, nos meses de Janeiro, fevereiro, março e abril, apresentando chuvas orográficas devido à altitude da Chapada do Araripe. A vegetação possui uma variedade de paisagens naturais, incluindo áreas de mata seca e floresta subcaducifólia tropical pluvial, principalmente nas áreas de vertentes encontramos mata úmida, no topo cerrado e o domínio da caatinga (floresta caducifólia espinhosa) com arbustos baixos e gramíneos.

A área próxima ao Caldeirão é composta de vegetação de caatinga e pastos pobre, devido o solo pedregoso, onde atualmente temos a criação de gado e ovinos, com plantação de feijão, milho e hortaliças. No caldeirão a dificuldade de se ter água potável é muito difícil, pois a área composta por rochas cristalinas o qual o nomeou a comunidade de Cal- deirão, encontra-se com pouco fluxo de água devido à seca desses cinco últimos anos que assola a região como um todo, não sendo possível o abastecimento humano.

Utilizamos como fonte para nossos alunos dois textos que tratam especificamente do Caldeirão de Santa Cruz do Deserto, assim como outras pesquisas já mencionadas. No texto de Gomes (2009) em que ele também consulta o trabalho de Cordeiro (2002; 2004), e mencionamos aqui o de Cordeiro (2008) foi possível apresentar aos nossos alunos como essa epopeia se construiu, na figura de um Beato, líder, messiânico e comunista? Assim os jornais da época o tratavam. José Lourenço, um negro líder, era filho de Lourenço Gomes da Silva e Tereza Maria da Conceição, naturais de Alagoas e domiciliados em Pilões de Dentro. A família emigrou para Juazeiro do Norte atraída pelos milagres e pela fama do padre Cícero, aonde chegaram por volta de 1890 (Gomes, 2009). Em 1890, José Lourenço acabou conquistando a amizade do famoso padre Cícero. O sacerdote o consagrou e o comissionou no ofício religioso de beato, depois de viverem alguns anos nas proximidades de Juazeiro e para se purificar dos pecados ele se integrou em algumas ordens de penitentes - pessoas que rezavam em cemitérios pelas almas do purgatório e que praticavam autoflagelação (Cariry, 2001; França, 2002).

Em 1894 José Lourenço arrenda um trecho do sítio Baixa da Anta, de propriedade do Sr. João de Brito, passa a receber inúmeras famílias de trabalhadores rurais, excluídos, miseráveis, enviadas pelo Padre Cicero. A comunidade religiosa permaneceu nesse sítio até 1926 (Gomes, 2009; Cordeiro, 2008). Segundo Cordeiro (2008) "as "comunidades" organizadas pelo Beato José Lourenço situavam-se na região do Cariri (região que compreende o Sul do estado do Ceará e o Noroeste do Estado de Pernambuco)" o Sítio Baixa Dantas, Caldeirão da Santa Cruz do Deserto e Mata dos Cavalos / Sítio Cruzeiro se localizavam no estado do Ceará precisamente no município de Crato; em Pernambuco, o Sítio União no município de Exú.

A comunidade do Caldeirão em que o líder era o Beato José Lourenço existiu entre os anos de 1894 e 1937 sempre em movimento devido à ordem burguesa exigir seus "direitos". Já para os moradores do Caldeirão esperavam o advento do reino messiânico, os romeiros mesmo diante da morte de Padre Cicero em 1934 afirmavam que ele não havia morrido. Estava no céu diante de Deus preparando o advento do reino de Deus na terra. Era a Terceira Pessoa da Santíssima Trindade. A manifestação do reino aconteceria precisamente na cidade de Juazeiro do Norte, na Igreja do Horto e no sítio do Caldeirão de Santa Cruz do Deserto, no município do Crato (Cordeiro, 2008; Gomes, 2009).

A mistura de crenças produziu um sincretismo religioso que caracterizava a religiosidade popular das terras secas no último quartel do século XIX e primeira metade do século XX, o governo do estado criou campos de concentração para os confinamentos dos refugiados da seca. A seca 
empurrava os flagelados para Baixa Dantas. Eles chegavam aos milhares. A comunidade crescia à medida que muitas famílias chegavam a Juazeiro - "a Meca do sertão" - sem ter trabalho, sem comida, sem moradia. Todos eram encaminhados pelo padre Cícero para os cuidados do beato. Padre Cícero, deu-lhe de presente um touro de raça a José Lourenço. O povo acreditava que o boi havia sido benzido pelo padre Cícero, e por isso seria portador de virtudes divinas. O touro recebeu o nome de Mansinho. Com o tempo, Mansinho passava a receber as efusivas manifestações de credulidade dos sertanejos. Enfeitavam-lhe os chifres com grinaldas de flores. Faziam-lhe oferendas de cargas de rapadura e de farinha (Cordeiro, 2008). Em 1936 a polícia invadiu o Caldeirão e com uma ordem judicial foram expulsos destruindo a comunidade segundo Cordeiro (2008) cerca de 1700 pessoas viviam em comunhão no local e seguiam o Beato. Em 1937 foram para o estado de Pernambuco e no Sítio União deram continuidade à comunidade até 1946, quando faleceu o Beato José Lourenço, os seus seguidores se dispersaram devido à ausência do líder.

Devido à história ser muito longa e encontrarmos muitos elementos que subjugam a comunidade do Caldeirão, assim como, certas especificidades relacionadas e seus termos, apontam-se nesse texto, sem poder alongar os motivos que foram construídos o Caldeirão e o que levou a destruição, foram motivos de análise nas aulas: à seca, messianismo, Beato, invasão, sociedade da época, trabalhadores rurais, representante da elite local, governo, igreja, "comunidade comunista", policia, força militar e um avião usado, boi mansinho, sincretismo religioso, Governador do Estado, aristocracia e fazendeiros do Crato, ordem dos Salesianos de Juazeiro, Diocese do Crato, perda da mão de obra para a comunidade e todas as fontes de boatos produzidos pela elite local.

No trabalho de Cordeiro (2008) valores antagônicos e confrontos de narrativas apontam para concepções que criam em função da interpretação dos acontecimentos em torno do Caldeirão. Para o Estado o Caldeirão foi pintado como um perigo à sociedade. 0 Caldeirão era visto como ameaça por terem cometido os "crimes" de romperem as relações de produção com o regime latifundiário e violar as leis da propriedade privada (Facó, 1976). Para os "remanescentes" o Caldeirão era um mundo de abundância e de igualdade em condições de vida, de trabalho e onde as necessidades mais profundas e essenciais dos seres humanos estavam satisfeitas (Cordeiro, 2008, p.12).

O sítio acabou por se transformar num lugarejo próspero com centenas de casas. Todas as casas eram de taipa - madeira, barro socado e palha. As moradias eram construídas de acordo com a ordem de chegada ao sítio, formando semicírculos direcionados para a área central onde havia uma igreja com um cemitério atrás e uma grande pátio a frente. Os equipamentos de produção, todos de uso coletivo, eram compostos de engenho de cana onde produziam rapadura (blocos de açúcar natural), casa de farinha onde produziam a farinha de mandioca, e paióis para armazenamento de colheitas de cereais. Graças à armazenagem, o Caldeirão pode alimentar flagelados da seca de 1932, uma das maiores registradas na história. A paisagem aos poucos foi modificando-se com a construção de dois grandes açudes e o cultivo de grande variedade de fruteiras. As artes e ofícios também tinham ali o seu lugar: havia oficinas de marcenaria, ferreiro, aviamentos de couro, barro e cerâmica. Cultivavam cereais, criavam bois, porcos, cabras, galinhas, animais de estimação domésticos (cães e gatos) e selvagens domesticados (emas, mocós, papagaios) - todos criados em liberdade, e alguns cavalos para uso do beato (Cordeiro, 2008, p.5).

Em entrevista a remanescentes e sobreviventes do Caldeirão, Cordeiro (2008) expõem:

A comunidade possuía um sistema de produção e distribuição de bens básicos (víveres, instrumentos, oportunidades de trabalho, moradia e "alimento para o espírito") com características de autogestão. Dizemos remanescentes que lá "tudo era de todos", e não havia distinção entre dirigentes e executantes do processo de produção. "Lá era assim, era amanhecer o dia e trabalhar, cada [qual ia] cuidar do seu serviço... Era tudo trabalhando junto, aquele grupo de gente, tudo trabalhando, tudo era um corpo de união, tudo junto... Trabalhando em qualquer serviço" (p.5).

Nessa narrativa histórica/geográfica sobre o Caldeirão de Santa Cruz do Deserto em conjunto com os alunos descobrimos uma sociedade peculiar que viviam em comunidade produtiva, em oração, penitência, seguindo as orientações de um líder, mas que diante da situação de seca e escassez de alimento e bens procuravam um lugar onde poderiam viver em paz, paz essa que não foi possível, pois o estado impõem limites à felicidade e organização de uma autogestão, que terminou com sua destruição. Para os alunos e professor o conteúdo pesquisado sobre o Caldeirão, o campo realizado, textos produzidos e as devidas análises se aproximarem do possível para a construção das instalações geográficas, passamos aqui ao ponto que tratamos sobre a obra, como se deu a construção por símbolos e signos dessa prática criativa. 

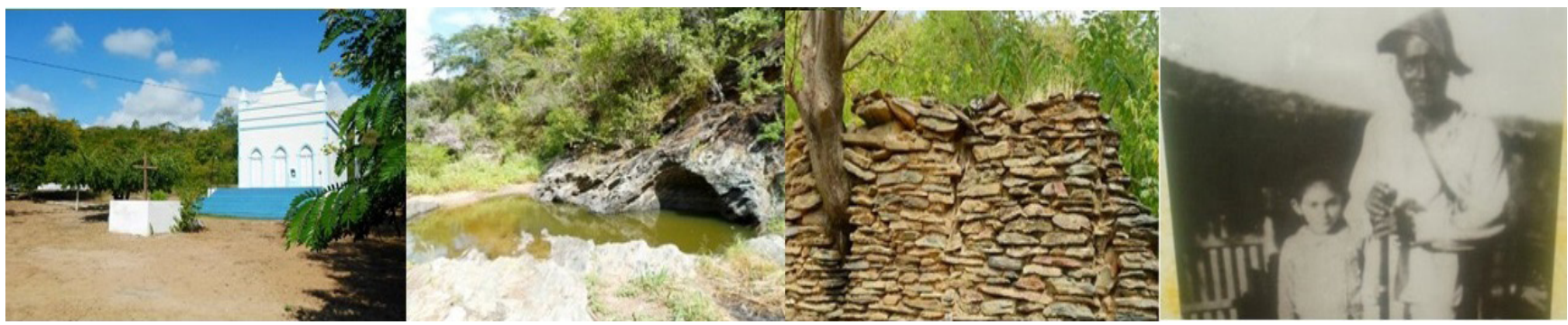

Figura 3. Da esquerda para a direita são: A Igreja, o Caldeirão um pequeno açude formado na rocha cristalina que resultou no nome da localidade, o Muro de Pedra fica atrás da igreja onde era o antigo cemitério e o Beato José Lourenço Fonte: Arquivo do autor.

\section{A obra}

Em Ribeiro (2014) definimos a Instalação Geográfica como uma forma de representação de um conteúdo geográfico pesquisado e trabalhado criativamente com signos e símbolos aplicado sobre materiais produzidos ou não pelo homem. Essa instalação pode ser montada na escola/universidade ou para além de seus muros atingindo uma dimensão social. A Instalação também é uma forma de expressão artística e geográfica que ao ser trabalhado no Ensino de Geografia, integrada aos conceitos geográficos e ao currículo, pode apresentar como um eixo importante para processo de avaliação de ensino e aprendizagem.

Em analogia ao espaço aqui especificamente o Sitio Caldeirão de Santa Cruz do Deserto e a geografia local, os alunos passam a contextualizar esse questionamento dos processos de relação de produção do espaço e da sociedade com olhar crítico, graças ao procedimento da avaliação construtiva que tem como uma das premissas a pesquisa objetiva e real, fazendo o uso das instalações. 0 termo instalações para o professor pesquisador tem ainda o sentido de dar forma a algo ou materializar o conteúdo estudado, pesquisado, por signos e símbolos conhecido, com o objetivo de apresentar e expressar algo, sentimento, sua visão de mundo, crítica aos paradigmas, é uma forma de expressão artística, que atende no nosso caso, um conteúdo geográfico.

Tentaremos explicitar os passos dessa construção:

- Em primeiro momento a partir de um conteúdo geográfico - sendo o conteúdo pesquisado, o Sitio Caldeirão e seus atores.

- Em segundo momento partimos para a produção de uma pesquisa, sobre a qual é elaborado um primeiro texto sobre o assunto abordado e apontando também o que irá ser materializado na instalação - aqui vamos expor os textos produzidos um por uma aluna e outro por um aluno.
Importante salientar que na etapa que chamamos de Teia das Ideias, (em sala os alunos dispostos em roda) são tratados e lidos todos os textos por eles produzidos, e em debate ajudamos uns aos outros a encontrar a melhor maneira de expor o seu tema dentro do conteúdo pesquisado. Não é possível sem a pesquisa o aluno elaborar os símbolos e signos. Nessa etapa da Teia das Ideias os alunos são instigados a "pensar aquilo que ainda não foi pensado", por exemplo; como representar a aristocracia da época, a classe mais abastada da cidade - com um "focinho de porco" isso foi materializado por outra aluna em sua instalação.

Na sequência apresentamos o texto produzido pelo aluno Antônio Pedro':

Esta etapa foi realizada no dia 15 de junho, foi uma experiência inédita e bastante interessante, confesso que quando foi proposta a ideia na sala eu fiquei tenso e inseguro, pois nunca tinha participado de nada semelhante, na sala de aula o professor Emerson Ribeiro dividiu temas para cada aluno, promovendo assim uma construção simbólica do caldeirão, o trabalho de cada um se definiu, o que gerou diversas ideias e instigou a criatividade.

Foi proposto que, usássemos uma mala e dentro dela colocássemos símbolos e signos referentes a peculiaridade do caldeirão que cada um iria abordar, ao pensar em um tema para desenvolver eu pensei bastante e refleti muito sobre a forma que iria abordar o meu ponto de vista do caldeirão, então escolhi abordar o paraíso almejado pelo beato, onde dei a nomenclatura de "Paraíso Decaído", por conta do massacre ocorrido, então produzi 4 símbolos.

Mesa (ora et labora) - simbolizava a igualdade entre a comunidade, e o alimento e o terço simbolizavam o trabalho e oração, onde todos produziam e consumiam, era um sistema que funcionava e promovia o bem-estar social de todos. Avião - simbolizava o estado, que promoveu o massacre, e também o primeiro ataque aéreo brasileiro que ocorreu no caldeirão.

1 Aluno do Estágio Supervisionado III em Geografia da Universidade Regional do Cariri-URCA. Texto apresentado no relatório de estágio pelo autor. 
Cruz ensanguentada (caldeirão) - simbolizava a cruz que o beato sempre levava que simbolizava a paz da comunidade, mas, após o massacre a cruz se mancha com sangue de inocentes, o que extermina a paz local, o caldeirão que apoiava a cruz simbolizava a estrutura física do local, e que através do sangue o caldeirão transborda e dispersa as pessoas do paraíso idealizado. Maleta - a mala simbolizava a fugas das pessoas do massacre, e o sangue na maleta simboliza o sangue das vítimas.

A experiência foi ótima, as pessoas que passaram por mim sempre demonstraram curiosas e dispostas a escutar, o que confirma que muitas pessoas não conhecessem a história do caldeirão, algumas pessoas estranharam aquela situação, onde pessoas bem vestidas estavam em uma praça pública com símbolos referentes ao caldeirão, considero que isso foi essencial para a curiosidade das pessoas, se não houvesse toda essa idealização não teria chamado atenção e muito menos conquistado o nosso objetivo, considero também que, essa prática pode e deve sim ser realizada no âmbito escolar, pois foge daquela aula expositiva e permite o aluno a se tornar construtor de um conhecimento, além de promover a relação escola-comunidade, no futuro como professor, pretendo reproduzir essa experiência, pois a considero válida e muito produtiva para a construção do saber.

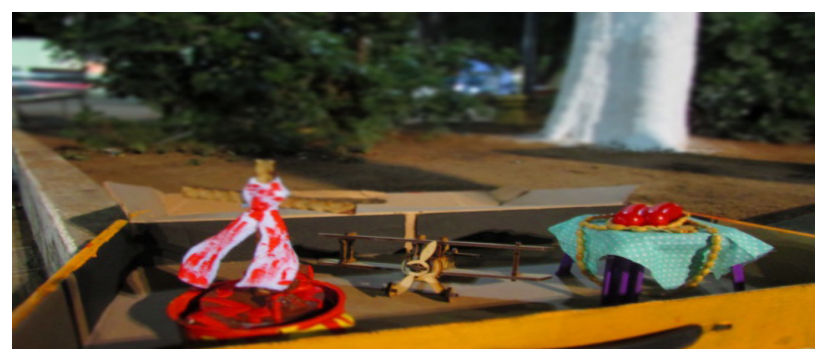

Figura 4. Símbolos e signos sobre o Caldeirão Fonte: Arquivo do autor.

A aluna Lyvia M. de Souza Alves² aponta no seu relatório a seguinte prática criativa:

No dia 15 de junho de 2016 foi apresentado na praça da Sé Crato Ceará, nossa instalação geográfica, na qual foi desenvolvida através de conteúdos simbólicos em uma mala, que caracterizou a comunidade Caldeirão da Santa Cruz do Deserto e os seus principais aspectos, físicos, culturais, ambientais e religiosos. Usei na minha mala de madeira cedida por uma senhora do município de Barro - Ce, segundo a mesma essa mala tem aproximadamente 80 anos de história, utilizei para esse trabalho os seguintes símbolos:

- Imagem de Padre Cicero, sendo um grande líder e instrutor do beato José Lourenço.

\footnotetext{
2 Aluna do Estágio Supervisionado III em Geografia da Universidade Regional do
} Cariri-URCA. Texto apresentado no relatório de estágio pela autora.
- Batina preta, símbolos que representam os trajes dos homens e do beato no Caldeirão.

- Bonecos de plásticos que representou a figura dos moradores da comunidade, destacando as áreas de produção agrícola de subsistência.

- Pequenos caixões, representando o massacre daquele povo e da perca de um sistema igualitário e de partilha que foi enterrado junto a população.

- Terço e velas que caracterizam a fé e devoção do povoado aos ensinamentos de Deus.

- Bonecos com armas de fogo e bombas, que caracterizou a violência que aquele povo sofreu das classes dominantes.

- Bonecosque representaram as pessoas ensanguentadas, passando o sofrimento e a morte de muitos inocentes do Caldeirão.

- Um pequeno Caldeirão, retratando a comunidade como um todo e caracterizando o quanto esse povoado foi importante na construção de uma possivel sociedade melhor.

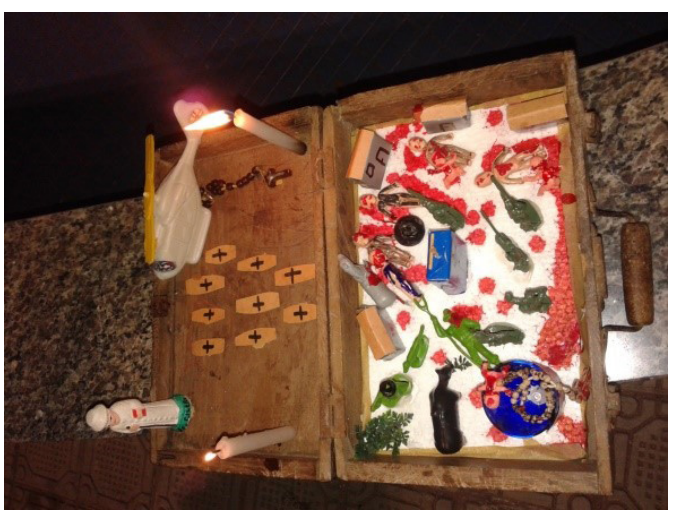

Figura 5. Performance, símbolos e signos sobre o Caldeirão Fonte: Arquivo do autor.

A experiência desse trabalho foi enriquecedora para meu processo de aprendizagem, já que essa é uma forma didática pedagógica que chama a atenção para os alunos, sendo uma atividade nova, que em seu caráter traz um diferencial, ver as pessoas que ali passaram admirados pela nossa criatividade, e atentos a história que retratávamos, foi gratificante. E com certeza é uma atividade ideal para aplicar futuramente na sala de aula. São vivencias assim, que nos tornará melhores professores, e com um diferencial para chegarmos ao ambiente escolar, gostaria de agradecer imensamente a meu professor Emerson Ribeiro pela oportunidade de nos mostrar novas ferramentas, que assim possamos nos espelhar e sermos bons professores. 
Abaixo apresentamos mais duas malas, uma com a representação do boi Mansinho, que era cultuado e tinha como sagrado para o povo por ser um presente de Padre Cicero, o boi foi alvo de perseguição pela elite local que diziam que os membros da comunidade adoravam como um Deus, esse boi foi morto. A outra por um focinho de porco tinha como representação a elite local, que desdenhava da comunidade messiânica, em que uns dos motivos eram que perdiam a mão de obra barata para o Caldeirão.

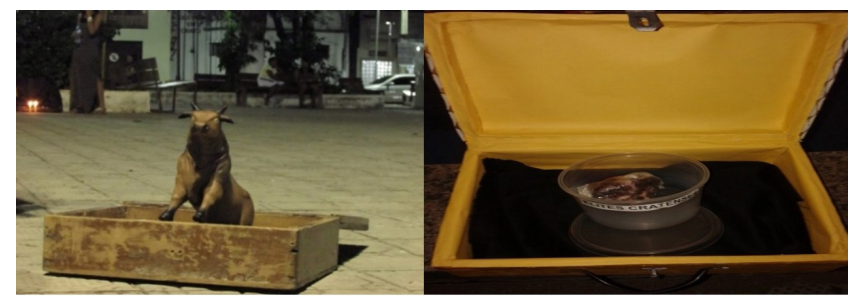

Figura 6. Boi Mansinho e focinho de porco

Fonte: Arquivo do autor.

Após apresentação na Praça da Sé na cidade do Crato em dia e local escolhido previamente em conjunto com os alunos, esses com traje social para a performance junto a mala, onde os alunos dominaram o conteúdo "Caldeirão de Santa Cruz do Deserto" explicando aos transeuntes, na apresentação de seus símbolos e signos, após uma hora de avaliação pública, as instalações se encerram.

E o último round é construção de um novo texto em sala de aula abordando o conteúdo e as impressões do público a respeito do trabalho, com isso finalizamos a prática, porém vale ressaltar que a pesquisa objetiva e real realizada pelos alunos sobre o tema permanece como aprendizado, atestamos, pois em encontro com os alunos já passado mais de 6 meses, o retorno do apreendido é fato, isso é possível porque os alunos construíram o seu conhecimento pela pesquisa e pela prática.

\section{Considerações sobre a Gênese}

A prática pedagógica demonstrada requer como qualquer outra uma metodologia, um percurso, uma rota, nem que seja essa de colisão, mas é necessário caminhar. As instalações geográficas como metodologia aponta a arte como um dos elementos didáticos para a geografia no processo de construção do ensino aprendizagem, sendo assim, o conteúdo proposto "Caldeirão de Santa Cruz do Deserto" se desloca no tempo e espaço para o conhecimento não só dos alunos, assim como, para os transeuntes presentes na Praça da Sé durante a apresentação.

Importante salientar que a história/geográfica do "Caldeirão" no município do Crato onde essa se realizou, não tem uma importância para a população atual, porque não consta em nenhum currículo escolar, ainda, sobre a população desconhecer tal fenômeno ocorrido, se deve também, na cidade do Crato especificamente ter um local que apresente esse recorte histórico. Para tanto, é oportuno dizer que algumas escolas fazem a visita levando seus alunos e agora brevemente a Igreja incentiva uma romaria ao local, onde temos um museu bem precário, a Capela, o Muro e o Caldeirão e uma família que cuida, essa recebeu da prefeitura a incumbência para zelar.

No entanto, nas duas visitas que fizemos uma somente os professores vendo a situação da Zeladoria do local, foi realizada pelos professores uma campanha junto aos alunos para levarem litros de água e alguns mantimentos na saída ao campo, pelo simples motivo que a prefeitura não envia há um bom tempo um carro pipa ao local e não fazendo o soldo combinado, não assistindo essa família que zela pelo local. É de suma importância relatar essa situação, pois o descaso político para com o nordeste brasileiro já se soma muitos anos, são muitos os autores que abordam o tema em questão, a própria história de perseguição pelas pessoas que viviam em harmonia no Caldeirão é apenas mais uma, entre tantas, como exemplo, Canudos.

A experiência teórica e prática aplicada aos alunos do Estágio Supervisionado III, em que a interdisciplinaridade, o movimento entre as turmas de Geografia, Economia e Antropologia, as leituras realizadas, o campo e as discussões em grupo, a construção de um texto junto à pesquisa de gabinete ajudou a construir o conhecimento dos alunos sobre o conteúdo proposto. Os alunos, professores e transeuntes passaram e tiveram a oportunidade de conhecer a história/geográfica do Caldeirão de Santa Cruz do Deserto, aplicada em instalações e performance na praça central da cidade do Crato. 0 trabalho apresentado ficou registrado em um vídeo que está hospedado no YouTube com o título de Janelas Geográficas que exemplifica o momento das instalações Geográficas apresentada pelos alunos do curso de Geografia do Estágio Supervisionado III. As memórias aqui levantadas, pesquisadas pelos alunos não se apagaram facilmente, pois a obra materializada na "mala" foi objeto e sujeito de uma construção histórica, foi desenvolvido por signos e símbolos remetendo-os a depurar o conteúdo na construção do conhecimento para o processo de ensino e aprendizagem.

\section{Referências}

Cariry, R. (diretor). (2001). o Caldeirão de Santa Cruz do Deserto [documentário]. Brasil: Cariri Filmes.

Cordeiro, D. (2002). Memórias e Narrações na Construção de um Líder, Beato José Lourenço. Dissertação de mestrado apresentada ao Departamento de Ciências Sociais e Filosofia do Programa de Pós-Graduação em Sociologia da Universidade Federal do Ceará, Fortaleza. 
Cordeiro, D. (2008). Caldeirão Da Santa Cruz: memórias de uma utopia comunista no nordeste brasileiro. Em Mundos sociais: saberes e práticas. Conferencia realizada no VI Congresso Portugues de Sociologia, Lisboa, Portugal.

Gomes, A. (2009). A Destruição da Terra Sem Males: 0 conflito religioso do Caldeirão de Santa Cruz do Deserto. Revista USP, (82), 54-68.

Facó, R. (1976). Cangaceiros e fanáticos. Rio de Janeiro: Civilização Brasileira.
Instituto Brasileiro de Geografia e Estadística (IBGE). (2018). Região Metropolitana do Cariri. Recuperado de: https://www.ibge.gov.br

Pinheiro, I. (2010). O Cariri. Fortaleza: Edições UFC.

Ribeiro, E. (2014). Processos Criativos em Geografia: Metodologia e Avaliação para a Sala de Aula em Instalações Geográficas (tese de doutorado). Universidade de São Paulo, São Paulo. 